\title{
PATRIMONIO CULTURAL INMATERIAL A TRAVÉS DE LA PLANIFICACIÓN PARTICIPATIVA EN SARAGURO. CASO INTI RAYMI COMUNIDAD LAS LAGUNAS, ECUADOR.
}

\author{
IMMATERIAL CULTURAL HERITAGE THROUGH PARTICIPATORY PLANNING \\ IN SARAGURO. CASE INTI RAYMI LAS LAGUNAS COMMUNITY, ECUADOR.
}

Rodrigo Medardo León Abarca, Msc.

Máster en Turismo, mención gestión del turismo (Ecuador).
Docente-Investigador de la Carrera de Turismo del Instituto Superior Tecnológico Juan
Montalvo, Loja, Ecuador.
rodrigo.leon@juanmontalvoloja.edu.ec
Julissa Elizabeth Angamarca Valdivieso, Ing.
Ingeniera en Administración Turística (Ecuador).
Autónoma, Ecuador.
yuli2607@hotmail.com

\section{ARTÍCULO DE INVESTIGACIÓN}

Recibido: 10 de junio de 2020

Aceptado: 17 de septiembre de 2020

\section{RESUMEN}

La investigación tuvo como objetivo contribuir al desarrollo turístico a través de la intervención en la fiesta del Inti Raymi del cantón Saraguro, provincia de Loja, con enfoque en el patrimonio cultural inmaterial y la participación activa de sus población; donde se caracterizó el territorio, diagnosticó la fiesta, identificó actores involucrados, problemas, necesidades, potencialidades, FODA, servicios y atractivos turísticos disponibles en la comunidad; a través de revisión bibliográfica, levantamiento de información en encuestas, fichas, talleres participativos y visitas de campo. Los resultados se basan en la participación activa de los actores locales y observación directa en la planificación y ejecución del Inti Raymi. Los resultados tienen el enfoque: 1) Analizar las características histórico-culturales del Inti Raymi, 2) Evaluar el potencial turístico del Inti Raymi. Referente al análisis de las características de la festividad se basó en entrevistas e investigación de antecedentes y actualidad de la festividad. En la evaluación del potencial turístico se utilizó la ficha de usos sociales, rituales y actos festivos (INPC), así como el MARPP como método de análisis rápido y planificación participativa; y para determinar el análisis de la demanda se realizó una encuesta de tres secciones: datos generales, perfil y percepciones. 
Palabras clave: turismo, turismo comunitario, inmaterialidad, festividad.

\section{ABSTRACT}

The objective of the research was to contribute to tourism development through an intervention at the Inti Raymi festival in the Saraguro canton, Loja province, focusing on intangible cultural heritage and the active participation of its population; where the territory was characterized, it diagnosed the party, identified involved actors, problems, needs, potentialities, SWOT, services and tourist attractions available in the community; through bibliographic review, information gathering in surveys, files, participatory workshops and field visits. The results are based on the active participation of local actors and direct observation in the planning and execution of the Inti Raymi. The results have the focus: 1) Analyze the cultural-historical characteristics of the Inti Raymi, 2) Evaluate the tourist potential of the Inti Raymi. Regarding the analysis of the characteristics of the holiday, it was based on interviews and research on the background and current events of the holiday. In the evaluation of the tourist potential, the sheet of social uses, rituals and festive acts (INPC) was used, as well as the MARPP as a method of rapid analysis and participatory planning; and to determine the analysis of demand, a survey of three sections was carried out: general data, profile and perceptions.

Keywords: tourism, community tourism, immateriality, festivity.

\section{INTRODUCCIÓN}

La interrelación entre patrimonio cultural y turismo es innegable e inevitable, ya que la humanidad desde su creación ha ido estructurando evidencia tangible e intangible; que ha formado el contexto histórico visible de la humanidad y debido a la creciente tendencia socioeconómica ha convertido en inversión para el sector económico, uno de ellos el turismo. El legado cultural evidenciado ha permitido la "construcción de espacios de encuentro común que fortalecen la identidad nacional, la diversidad, la plurinacionalidad y la interculturalidad" (Asamblea Nacional, 2013).

En la región sur del Ecuador pluricultural y multiétnico se encuentra en cantón Saraguro, región donde predomina la etnia Saraguro considera la más pura de América y uno de los pueblos de origen Inca más antiguos de la región, su territorio constituye un testimonio vivo y transcendente de os hechos históricos, culturales, arquitectónica y arqueológica que da la identidad al pueblo, tal es el caso de la Comunidad Las Lagunas cuyos habitantes viven de la agricultura, ganadería, artesanías, sector de servicios y turismo comunitario; es un lugar para 
realizar caminatas a terrazas agrícolas y pucarás, se realizan rituales indígenas y visitas a talleres artesanales y textiles.

En Saraguro se desarrollan diferentes prácticas relacionadas al Alli Kawsay (buen vivir) conservada por sus ancestros y que se recrean en el espacio - tiempo llamado Nawpa Kawsay (concebida como el tiempo circular entre pasado y futuro); entendidas como cultura la forma de vida y el comportamiento colectivo de un grupo social determinado (Cartuche Paqui \& Bastidas Andrade, 2017). Las Lagunas se realiza la fiesta del Inti Raymi, la celebración más importante y representativa del año, aquí se reviven las tradicionales costumbres de este pueblo indígena, manteniendo su valor cultural compuesto de música, danza, ritualidad y gastronomía.

El turismo cultural en Saraguro no está debidamente promocionado y aprovechado, más bien se lo ha folklorizado con la finalidad de obtener un lucro económico; frente a este problema es importante que la propia comunidad de forma activa planifique y ejecute el Inti Raymi para rescatar y potenciar su identidad cultural a la par de fomentar el desarrollo turístico a través del PC inmaterial y participación colectiva. En el contexto turístico, el desconocimiento y falta de aprovechamiento del patrimonio histórico-cultural de esta festividad han sido limitantes para la revitalización del patrimonio.

En la actualidad varios son los factores que intervienen en los cambios que ha tenido el Inti Raymi, el riesgo es de perder su verdadero significado, ya que se combina la cultura con elementos modernos en donde se mestiza la celebración de la fiesta para generar participación de los más jóvenes de la comunidad, otra de las limitantes es la falta de difusión por parte de las instituciones públicas y privadas, porque al no ser difundida pierde la oportunidad de generar la visita de turistas nacionales como extranjeros.

\section{REVISIÓN TEÓRICA}

\section{Patrimonio cultural espíritu del desarrollo turístico}

El patrimonio cultural y turismo son interrelaciones inevitables e inseparables; en inicio, se consideran conceptualmente independientes debido a sus propias condiciones y características, pero cuando se refieren a actividades turísticas, son completamente relacionados ya que responden a la evolución de la sociedad y cultura. EI PC se remonta a la Antigua Roma, época en que la propiedad familiar ya se la concebía heredable y se transfería de generación en generación, a la cual los miembros de un grupo familiar tenían derecho. (Engels, 1996). Lo que Engels conceptualiza, corresponde a bienes heredados con el valor económico de los activos adquiridos entre generaciones (padre-hijo), sin descartar, la acepción jurídica desde el enfoque de objetos materiales, tanto en el cumplimiento de obligaciones y derechos sobre los mismos. 
Según se profundiza en la idea de patrimonio se va comprobando la enrevesada complejidad que hay detrás del término; si primero se ha visto que su aparición surge en conexión con el nacimiento de los nacionalismos y con función claramente cohesionante, también su interpretación evoluciona con el tiempo y, en arreglo a ello, va adquiriendo nuevas posibilidades y funciones, entre ellas el uso como bien de consumo, en ocasiones priorizado frente a lo identitario. Las posibilidades del patrimonio en conjunción con la empresa turística o -tal vez más apropiado sería referirse a esta simbiosis de la forma inversa- las ventajas que, para la empresa turística, asociada al ocio y, este en sí a la banalidad, supone revestirse de dignidad a través del aparente enriquecimiento intelectual que ofrece el patrimonio, genera una riqueza monetaria que convierte a este multisector en la primera fuente de ingresos en muchos países.

Sin embargo, esta función económica, aunque a veces se priorice o parezca incluso inconexa de la identitaria, no debe ser vista como un desarrollo ni enfrentado, ni ajeno, a su función social sino producto de una misma complejidad integradora. Una visión excesivamente económica, propia de los materialistas llega a caer en una "teología del capitalismo" que obvia otras realidades sociales y mentales, que afectan a todo el sistema organizativo y no sólo al productivo.

El turismo en Latinoamérica es una de las mayores fuentes de ingresos, la revolución de los transportes tal vez son factores que puedan explicar las primeras oleadas de turistas, prestando atención a esa accesibilidad, el deseo de relax y la temporal democratización de los placeres que supone, pero desde los años 90 se da una tendencia nueva que ha venido a llamarse "turismo alternativo".

El turismo alternativo, bajo sus distintas formas - etnoturismo, ecoturismo, turismo rural, turismo religioso, turismo de aventura y turismo cultural- busca la posibilidad de encontrar nuevos destinos que antes no eran susceptibles de ser visitados, por ello tiene especial incidencia en comunidades con cosmovisiones diferentes a la occidental dominante. Ante esta situación se dan dos posiciones:

a. Para muchos el turismo se convierte en una nueva variedad de colonialismo; ejerce una presión sobre la comunidad visitada que acaba modificando pautas económicas, sociales y comportamiento, en paulatino detrimento de elementos culturales propios y a favor de la adquisición de los venidos junto con el visitante. Con todo, como señala Santana, surge una "cultura del encuentro" que no es ninguna de las dos culturas matrices, sino una miscelánea, en la que turista y anfitrión adquieren unos roles predefinidos que determinan la forma de interactuar entre ambos grupos (Santana Talavera, 1997)

b. Tal como lo manifiesta Skoczeck (cit en Chávez Dagostino \& Andrade Romo 2002), para sus partidarios, supone un fomento del contacto con la naturaleza, tradición, pasado perdido 
con poblaciones nativas, revitalización de la vida de muchas sociedades locales y de mayor

preocupación por su impacto medioambiental.

Irónicamente esta búsqueda de raíces, de lo perdurable frente a lo volátil, no refuerza una nueva conciencia más cercana a otras cosmovisiones, sino que el contacto con los otros (campesinos o indígenas) refuerza nuestra individualidad y sobre todo la continuidad de nuestro propio sistema, ya que son identificados como formas extintas no recuperables por nosotros sino como meros esbozos anecdóticos que visibilizan, por su contraste, los logros de nuestra sociedad; aunque por ello mismo se tome la premisa de "conservar a toda costa" bajo la idea de "desarrollo sostenible". Así, se vigoriza la reproducción de estilos de vida, ya que el turista demanda las mismas "comodidades" que en su lugar de origen con lo que se anticipa un mundo homogeneizado en la democracia y el consumo.

\section{Patrimonio Cultural: Inmaterialidad.}

El Patrimonio es la herencia materia e inmaterial que recibimos de nuestros antepasados, forma parte de nuestra historia y nos hace únicos como pueblo; conocer nuestro patrimonio nos da sentido de pertenencia, fortalece nuestra identidad y nos ayuda a valorar lo que tenemos; patrimonio se suele entender como el acervo de una sociedad, esto es, el conjunto (materiales o inmateriales) acumulados por tradición o herencia, común al conjunto de los individuos que constituyen esa sociedad; también es entendido como un legado o herencia, es decir, de algo que es recibido, normalmente del pasado, o que se posee porque es dado. (Troncoso \& Almirón, 2005)

Todos los expertos en patrimonio cultural reconocen así sus 2 aspectos claves: el Patrimonio es creación - invención y construcción social. Sin embargo, algunos darán prioridad en su discurso al primer aspecto, y otros al segundo. Es importante de reconocer porque para quienes prima el carácter inventivo se destaca la idea de manipulación (Hobsbawnm, 1988, cit por Prats, 1997), mientras que para quienes inciden en su carácter de construcción social lo esencial es la idea de "universos simbólicos legitimados" (Berger, 1983, cit por Prats, 1997). Lo primero que cabe reconocer que el patrimonio es algo creado, no es algo natural, es cuándo, dónde y porqué tiene su origen.

En comparación con el patrimonio material, el inmaterial aparece como menos sustancial, menos duradero y en consecuencia con un menor valor evidente; es fundamental que se construyan procesos de valoración y fortalecimiento de este patrimonio (Centro Regional de Investigaciones Multidisciplinarias, 2013). El patrimonio inmaterial, comprende los usos, representaciones, expresiones, conocimientos y técnicas, junto con instrumentos, objetos, 
artefactos y espacios culturales que les son inherentes a comunidades, grupos y en algunos casos individuos, reconozcan como parte integrante de su PC; se transmite de generación en generación, es recreado constantemente por comunidades y grupos en función de su entorno, interacción con la naturaleza e historia, infundiéndoles un sentimiento de identidad y continuidad, contribuye así a promover el respeto de la diversidad cultural y la creatividad humana.

El patrimonio cultural inmaterial es:

- Tradicional, contemporáneo y viviente a un mismo tiempo; no solo incluye tradiciones heredadas del pasado, sino también usos rurales y urbanos contemporáneos característicos de diversos grupos culturales.

- Integrador, podemos compartir expresiones del PC inmaterial que son parecidas a las de otros. Tanto si son de la aldea vecina como de una ciudad en las antípodas o han sido adaptadas por pueblos que han emigrado; se han transmitido de generación en generación, han evolucionado en respuesta a su entorno y contribuyen a infundirnos un sentimiento de identidad y continuidad, creando un vínculo entre el pasado - futuro a través del presente.

- No se presta a preguntas sobre la pertenencia de un determinado uso a una cultura, sino que contribuye a la cohesión social fomentando un sentimiento de identidad y responsabilidad que ayuda a los individuos a sentirse miembros de una 0 varias comunidades y de la sociedad en general.

- Representativo, no se valora simplemente como un bien cultural a título comparativo, por su exclusividad o valor excepcional. Florece en las comunidades y depende de aquéllos cuyos conocimientos de las tradiciones, técnicas y costumbres se transmiten al resto de la comunidad, de generación en generación.

- Basado en la comunidad, sólo puede serlo si es reconocido como tal por las comunidades, grupos o individuos que lo crean, mantienen y transmiten. Sin este reconocimiento, nadie puede decidir por ellos que una expresión o un uso determinado forman parte de su patrimonio (UNESCO, 2003).

Bajo este contexto es fundamental salvaguardar el patrimonio inmaterial, referente a "Usos sociales, rituales y actos festivos" que de acuerdo al ente coordinador de la protección patrimonial del Ecuador INPC (2017) estas actividades son las que estructuran la vida de las comunidades y grupos sociales reafirmando su identidad, realizados en espacios públicos o privados, contextos sagrados o profanos, en el área rural o urbana y que pueden estar asociadas al ciclo vital de los individuos y grupos, al calendario agrícola o estacional y otros sistemas espaciales y temporales entre las que se puede incluir: las fiestas, las prácticas comunitarias tradicionales, los ritos. 
Hoy en día, el patrimonio cultural está estrechamente relacionado con los desafíos más apremiantes que enfrenta la humanidad. Estos desafíos incluyen el cambio climático y los desastres naturales, educación, salud, inmigración, urbanización, conflicto entre comunidades, marginación o desigualdad económica. Por lo tanto, el patrimonio cultural y turismo se consideran "una condición necesaria para la salvaguardia y promoción del desarrollo social, ambiental y económico pacífico y sostenible".

\section{MATERIALES Y MÉTODOS}

La investigación estableció un proceso ordenado y lógico en el cual, para poder fortalecer los valores culturales del Inti Raymi, se utilizó una metodología adecuada:
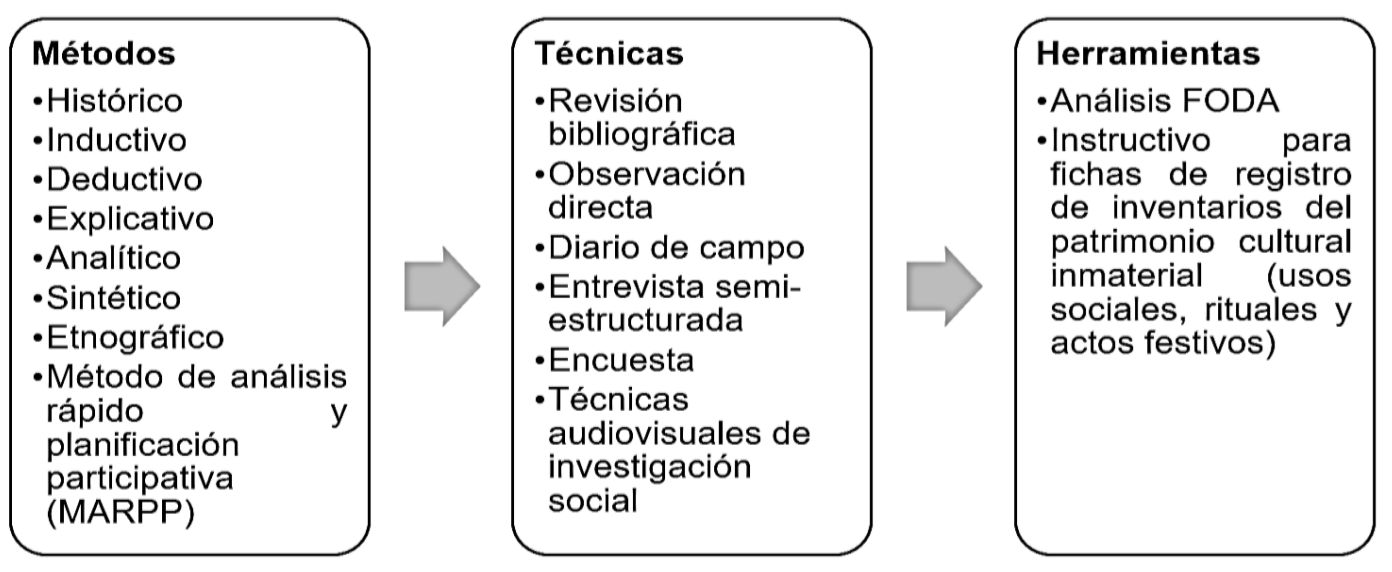

Figura 1. Proceso metodológico

Fuente: Elaboración propia.

Desde el enfoque metodológico la investigación fue descriptiva y de carácter cualitativa. Descriptiva a través de la observación y descripción del comportamiento de un sujeto sin influir sobre él de ninguna manera (Explorable, 2018). En este contexto, no se pueden obtener conclusiones generales, ni explicaciones, sino más bien descripciones del comportamiento de un fenómeno dado (Fundación Dra. Silvia Macotela, 2018). Así respecto a la cualitativa, esta recogió información basada en la observación de comportamientos naturales, discursos, respuestas abiertas para una posterior interpretación (SINNAPS, 2018).

El estudio estuvo abordado en 2 fases, correspondientes a cada objetivo de la investigación: 


\section{Fase 1}

Analizar las características

\section{Fase 2}

Evaluar el potencial turístico del Inti Raymi

histórico-culturales del Inti

Raymi

Figura 2. Fases de la investigación

Fuente: Elaboración propia.

Para "Analizar las características histórico-culturales del Inti Raymi", se utilizó los diferentes métodos investigativos que facilitaron la recopilación de información general de la comunidad, al igual que información social y cultural del proceso del Inti Raymi. Además, para el diagnóstico actual del Inti Raymi y de la comunidad se consideró la ficha de levantamiento de información de Ricaurte del "Manual para el diagnóstico turístico local - Guía para planificadores", concluyendo que el diagnóstico turístico es la etapa del proceso de planificación, donde se determinan y evalúan las condiciones de destino. El manual muestra las fases de diseño del diagnóstico de la situación actual (Figura 3), recolección de información de campo (fichas), taller FODA (actores locales relacionados al Inti Raymi en la comunidad), análisis y sistematización de resultados.

\section{FASE 1}

\section{Revisión de información secundaria}

\begin{tabular}{ll|}
\hline - & Documentos \\
- & Audiovisuales \\
- & Archios web \\
\hline
\end{tabular}

\section{Levantamiento de información de campo}

- Ficha Diagnóstico turístico

- Ficha Caracterización de la demanda

- Ficha de caracterización de atractivos y recursos turísticos

Figura 3. Diseño de la estructura del diagnóstico del territorio.

Fuente: Elaboración propia.

Para fundamentar y verificar la información se realizaron entrevistas a actores claves de la estructura social-cultural de la comunidad en donde se determinó la historia, origen y su desarrollo antes-durante y después.

Para "Evaluar el potencial turístico del Inti Raymi", principalmente se utilizó la ficha de inventario de "Usos Sociales, Rituales y actos Festivos INPC", que permitió recolectar la información de esta manifestación cultural. Posteriormente se utilizó diversos métodos y técnicas de investigación que permitieron verificar hechos históricos y actuales de la celebración. Además, el 21 de junio, día de la celebración mayor del Inti Raymi se aplicó 157 encuestas a los turistas 
asistentes para conocer el nivel de satisfacción en relación a este evento, para lo cual se utilizó la fórmula de muestreo probabilístico aleatorio simple para población infinita, la misma que se consideró debido a que no se tuvo datos reales de los visitantes asistentes a la fiesta. El perfil de los encuestados fue direccionado a turistas provenientes del resto de cantones de la provincia de Loja y Azuay principalmente, por ser los lugares más cercanos a Saraguro; sin embargo, existieron también turistas del resto país y extranjeros en menor demanda.

\section{FASE 2}

\begin{tabular}{|c|c|}
\hline Perfil del turista & Percepción del evento \\
\hline $\begin{array}{ll}\text { - } & \text { Nacionalidad } \\
\text { - } & \text { Residencia } \\
\text { - } & \text { Profesión } \\
\text { - } & \text { Edad } \\
\text { - } & \text { Nivel de estudios } \\
\text { - } & \text { Nivel de ingresos } \\
\text { - } & \text { Género }\end{array}$ & $\begin{array}{ll}\text { - } & \text { Motivación asistir Inti Raymi } \\
\text { - } & \text { Información de acceso al Inti Raymi } \\
\text { - } & \text { Debilidades informativas de la fiesta Inti Raymi } \\
\text { - } & \text { Contenido informativo de promoción } \\
\text { - } & \text { Atractivos turísticos en la comunidad Las Lagunas } \\
\text { - } & \text { Actividad turística vinculada al Inti Raymi } \\
\text { - } & \text { Gasto promedio en la fiesta Inti Raymi }\end{array}$ \\
\hline
\end{tabular}

Figura 4. Diseño de la estructura del análisis de la demanda.

Fuente: Elaboración propia.

Finalmente, se aplicó el "método de análisis rápido y planificación participativa", donde se desarrolló un taller participativo como proceso de aprendizaje interactivo y rápido, con la finalidad para entender la realidad del Inti Raymi; conjuntamente con los asistentes se elaboró el FODA de la festividad, así como la propuesta de fortalecimiento.

\section{ANÁLISIS DE RESULTADOS}

\section{Fase 1: Analizar las características histórico-culturales del Inti Raymi. Caracterización turística de la comunidad Las Lagunas}

Saraguro pueblo de origen legendario que data de la cultura incásica, donde conviven dos culturas: la etnia Kichwa Saraguro y los mestizos; quienes llegaron durante la colonia e inicios de la república que lo hacen un escenario propicio para el desarrollo turístico. Las Lagunas está ubicada a $2 \mathrm{Km}$ del área urbana de la parroquia Saraguro.

Población: La problemática que conlleva la migración ha ocasionado que la población de la comunidad disminuya en los últimos años, según el plan estratégico de la comunidad se estima que la población masculina representa el $47.47 \%$ y las mujeres el $52.53 \%$ del total de la población. (Comunidad Lagunas, 2010) 
Tabla 1

Habitantes por familias de la comunidad

\begin{tabular}{cc}
\hline Barrio / Sector & Población \\
\hline Yarimala & 26 familias \\
Rarik Pukro & 19 familias \\
Tajshana & 41 familias \\
Waile & 22 familias \\
Lirios & 23 familias \\
Guabo Loma & $\mathbf{3 5}$ familias \\
\hline Total & $\mathbf{1 6 6}$ familias \\
\hline
\end{tabular}

Fuente: Elaboración propia.

En la información socioeconómica se pudo establecer que la comunidad cuenta relativamente con los servicios básicos que contribuyen al desarrollo del territorio, pero fue claro que estos elementos se deben mejorar sustancialmente.

Tabla 2

Información socioeconómica

\section{Información Socioeconómica}

Educación Existe el centro educativo comunitario “Inti Raymi”; en la actualidad ejecuta una
propuesta basada en los principios de la cosmovisión andina.

\begin{tabular}{|c|c|}
\hline Salud & $\begin{array}{l}\text { La comunidad cuenta con un sub centro de salud equipado adecuadamente que } \\
\text { brinda servicios a varias comunidades aledañas como llincho y Gunudel. }\end{array}$ \\
\hline $\begin{array}{l}\text { Producción } \\
\text { Agrícola }\end{array}$ & $\begin{array}{l}\text { La producción agrícola se basa en la chacra que consiste en cultivar el maíz en } \\
\text { asocio con el fréjol, haba, calabaza (zambo), melloco, papa, etc., como parte de una } \\
\text { tecnología ancestral andina y a pesar que cada familia tiene definido su principal } \\
\text { fuente de producción, realizan actividades complementarias como ganaderas, } \\
\text { elaboración de artesanías, etc. }\end{array}$ \\
\hline Vivienda & $\begin{array}{l}\text { Existen casas de diferente tipo, la casa tradicional es fabricada de adobe o } \\
\text { bareque y cubierta de teja; pero también se construyen casas de hormigón con } \\
\text { bloque o ladrillo; pero, en la actualidad las viviendas deben ser construidas con } \\
\text { materiales del medio, cubierta de teja. }\end{array}$ \\
\hline $\begin{array}{l}\text { Identidad e } \\
\text { idioma }\end{array}$ & $\begin{array}{l}\text { El } 99 \% \text { de la población de la comunidad pertenece al pueblo Kichwa Saraguro, } \\
1 \% \text { es mestizo; } 95 \% \text { de la población mantiene la indumentaria propia; del cual, } 20 \% \\
\text { es elaborada en lana de oveja y } 80 \% \text { elaborada con fibras sintéticas. En la } \\
\text { comunidad se habla castellano y su idioma natal Kichwa. }\end{array}$ \\
\hline
\end{tabular}

Fuente: Elaboración propia. 
Organización Política: La organización política se maneja bajo el sistema de gobierno democrático electo en asamblea general, cuyo periodo dura 2 años, las dignidades que se atribuyen son:

- Kapak $^{1}$

- Vicepresidente

- Secretario

- Tesorero

- Mayorales

- $\quad$ Comisiones especiales.

$Y$ existen diferentes sub organizaciones con un trabajo o responsabilidad específica siempre en coordinación con el consejo de gobierno.

Tabla 3

Sub - Organizaciones de la Comunidad Las Lagunas

\begin{tabular}{l|l}
\hline \multicolumn{1}{c|}{ Sub - Organizaciones } & \\
\hline Centro de Desarrollo Infantil & \\
\hline Centro educativo comunitario Inti Raymi & \\
\hline Grupo de jóvenes Runa Kawsay & \\
\hline Centro de mujeres & \\
\hline Sub centro de salud & \\
\hline Grupo de productores agropecuario & \\
\hline Grupo de pastoral & \\
\hline Grupo de alcohólicos anónimos & \\
\hline
\end{tabular}

Fuente: Elaboración propia

Con el apoyo de los actores claves se estableció en la comunidad los siguientes atractivos turísticos:

Tabla 4

Atractivos turísticos

\begin{tabular}{l|lcl}
\hline \multicolumn{4}{c}{ Atractivos turísticos - Comunidad Las Lagunas } \\
\hline Naturales & Bosque Protector Huashapamba & Cascada Tinajilla & Río Chuchuchir \\
\hline Culturales & Artesanías Orfebrería & La piedra del Ushnu & Telares-Folklor \\
\hline
\end{tabular}

Fuente: Elaboración propia.

${ }^{1}$ Kapak: presidente. 
Las Lagunas cuenta con alojamientos comunitarios equipados adecuadamente que deseen compartir su forma de vida diaria, todos los prestadores de servicios están afiliados a la "Red de turismo comunitario Saraguro Rikuy".

Tabla 5

Alojamiento comunidad Las Lagunas

\begin{tabular}{|c|c|c|c|}
\hline \multicolumn{4}{|c|}{ Alojamiento Comunitario } \\
\hline Hospedaje & Representante & Capacidad & Servicios \\
\hline Inka Wasi & Baudillo Quizhpe & $4 \operatorname{Pax}$ & \multirow{3}{*}{$\begin{array}{l}\text { Alojamiento + alimentación + } \\
\text { convivencia familiar/comunitaria }\end{array}$} \\
\hline \multirow[b]{2}{*}{ Casas } & Miguel Quizhpe & $2 \mathrm{Pax}$ & \\
\hline & $\begin{array}{rr}\text { Rosa } & \text { Vicenta } \\
\text { Guamán } & \end{array}$ & 3 Pax & \\
\hline Alimentación & \multicolumn{3}{|c|}{$\begin{array}{l}\text { El servicio de alimentación es mediante contrato; el paquete incluye } \\
\text { alimentación, alojamiento y esparcimiento. }\end{array}$} \\
\hline Esparcimiento & \multicolumn{3}{|c|}{$\begin{array}{l}\text { Existen canchas deportivas y peña-bar que es solo para el entretenimiento } \\
\text { de los turistas que optan por el turismo comunitario (Inka Wasi). }\end{array}$} \\
\hline
\end{tabular}

Fuente: Elaboración propia.

Fiestas: Tradicionalmente, la fiesta de la comunidad se realizaba el 1 de mayo de cada año y se festejaba el día del trabajo y cristianamente el día de San José Obrero; desde hace muchos años se ha dado un proceso de cambio implementándose en la comunidad la celebración del Inti Raymi con una visión andina en el mes de junio. Las Lagunas es la sede del Inti Raymi (21 de junio), afianzando en el ciclo vital Kawsay ${ }^{2}$ que rige el desarrollo del ser humano; así la concepción, nacimiento, crecimiento, madurez y muerte son los rectores del ciclo vital. El Kawsay está presente en todos los seres vivientes; los hombres expresan su conexión con la naturaleza y lo trascendente a través de lo festivo, mítico y ritual. (GAD Municipal Intercultural de Saraguro, 2016)

\section{Diagnóstico general del Inti Raymi}

Para el inicio del proceso del diagnóstico a más de las fuentes bibliográficas, se establecieron actores claves preponderantes para la comunidad y la festividad, mediante el uso de la técnica de bola de nieve se identificaron los actores locales del territorio, que tienen incidencia directa en el desarrollo de la comunidad y la festividad.

2 Kawsay: desarrollo del ser humano 
Tabla 6

Actores claves

\begin{tabular}{|c|c|}
\hline \multicolumn{2}{|r|}{ Actores Claves } \\
\hline \multirow{2}{*}{ Entrevistas } & Benigno Zhingre: Centro Educativo Intercultural Bilingüe Inti Raymi. \\
\hline & Baudilio Quizhpe: Red de Turismo Comunitario "SARAGURO RIKUY" \\
\hline \multirow{7}{*}{$\begin{array}{c}\text { Taller } \\
\text { participativo }\end{array}$} & Grupo de jóvenes Runa Kawsay \\
\hline & Centro de mujeres \\
\hline & Inka Wasi: hospedaje comunitario \\
\hline & Habitantes de la comunidad en general \\
\hline & GAD Provincial de Loja: apoyo emprendimientos productivos. \\
\hline & $\begin{array}{l}\text { GAD Municipal Intercultural Saraguro: fomenta el desarrollo turístico } \\
\text { conjuntamente con los gobiernos parroquiales y actores locales. }\end{array}$ \\
\hline & INPC: regula y fomenta la protección de los valores culturales del territorio. \\
\hline
\end{tabular}

Fuente: Elaboración propia.

Antecedentes del Inti Raymi. La expansión del imperio Inca incorporó a diferentes pueblos de la sierra, a pesar de que este estado impuso un modelo organizativo, socio económico, político y cultural, éste no era ajeno a lo que tenían los pueblos originarios, ya que tenían sistemas desarrollados a partir de la realidad agraria andina. En el aspecto religioso, tenían como divinidades al sol, la luna y otros elementos de la naturaleza; los Incas generalizaron el culto al sol y le dieron un carácter estatal (Silva Charvet, 2005). Este proceso duró aproximadamente un siglo y fue interrumpido por la invasión española, quienes en estas tierras encontraron una riqueza inagotable para la corona española y la iglesia; con el afán de explotarlos utilizaron como métodos más comunes la masacre brutal, engaño y tortura; iniciaron el aniquilamiento de la población indígena (Irving en Coll, 1980, p. 25). En todo este caminar y como una forma de resistencia a los diversos cambios experimentados como comunidades indígenas, Las Lagunas propone la recuperación del pensamiento andino bajo el lema: "Volver a vivir como Runas".

La llegada y establecimiento de colonias españolas tuvo consecuencias muy graves para los indígenas, se destruyeron valores importantes de los pueblos indígenas; una de ellos la celebración de los Raymis, entre ellas la fiesta del Inti Raymi, en ese tiempo se trató de ocultar toda la sabiduría, conocimiento, y el camino de la vida del pueblo indígena, la misma que a partir del año de 1490 quedó en la obscuridad. En la década del 80 a partir de una vuelta del Pachakutik que son 500 años aproximadamente, vuelve a reflorecer esta fiesta en la comunidad Las Lagunas 
(antiguamente comunidad Chukidel Ayllullakta), como un proceso de reivindicación, visto por los jóvenes a manera de una nueva visión y de un sentir comunitario de un pueblo andino.

Las fiestas andinas son 4 de acuerdo al calendario agroecológico, acorde al ciclo de la chakra, orientados en relación a los 2 solsticios y 2 equinoccios, desde esta perspectiva el equinoccio del otoño comienza donde el campo está vacío, esto para el mundo andino es la celebración del Kulla Raymi o Killa Raymi, una celebración femenina que comienza cuando el campo se empieza arar, preparando así la tierra para colocar la semilla, es la época de la fertilidad, luego viene el Kapak Raymi, donde la planta del maíz ha alcanzado una altura que se llama la macolla ${ }^{3}$, es la fiesta de la aceptación del poder del ser humano como tal, es decir el poder adquirido con un compromiso para la comunidad y familia, se hace en el mes de septiembre en el solsticio de invierno.

Luego se pasa al Paukar Raymi, otra fiesta femenina de florecimiento de la mujer doncella, de la juventud específicamente y coincide con el ciclo agrícola del maíz que está en época de floración; y finalmente el Inti Raymi es la época de prender el fuego, es la fiesta de las cruces, de las vírgenes, es la época del dios sol. El Inti Raymi es una celebración que los pueblos andinos ancestralmente lo hacían como parte de un eje que direcciona la vida y a la sociedad, para el mundo andino, con el Inti Raymi termina el ciclo agrícola, y comienza otro, es así como se cumple el Pachakutik. ${ }^{4}$

El significado del Inti Raymi es la pascua de relación entre el sol (yaya inti) y las personas; en Las Lagunas el Inti Raymi comienza desde 1987 impulsado por un grupo de jóvenes llamados "Runa Kawsay", apoyados por el grupo cultural de Saraguro, quienes conjuntamente empiezan a celebrar la fiesta, pero de carácter folklorista, intentando dar otra imagen e idea de fiesta, en aquella época se empezó a rechazar lo que la iglesia imponía. En ese contexto hubo una lucha ideológica entre los jóvenes, los mayores de la comunidad y la iglesia; y como la iglesia estaba atada a los mayores hubo un gran enfrentamiento, pero a pesar de eso desde entonces se ha celebrado la fiesta.

Se crea una institución educativa "Inti Raymi”, que asume el compromiso de apoyar este proceso, se empieza a generalizar, profundizar y a sostener desde el punto de vista cultural, histórico y espiritual, en estas fiestas se evita el consumo de alcohol, precisamente porque son

\footnotetext{
${ }^{3}$ Macolla: planta del maíz de altura más o menos de $1 \mathrm{~m}$. donde ya tiene formada todas sus hojas.

4 Pachakutik: cumplir un ciclo y continuar otro, no es que el ciclo viene al mismo punto si no que se va abriendo y ahí se da la espiral y esa espiral es el Pachakutik.

${ }^{5}$ Runa Kawsay: que identifica a un grupo de jóvenes dentro de la comunidad, simboliza el contexto del que hacer de las personas de los pueblos andinos, Runa-Ser humano, Kawsay vida.
} 
fiestas para lograr el punto equilibrio y armonía de la comunidad, siendo un hecho de carácter cultural y espiritual ya que estas fiestas son el centro de aprendizaje para los niños y jóvenes.

Antiguamente los Kurakas ${ }^{6}$ que llegaban al Inti Raymi traían sus mejores galas e invenciones, algunos vestidos chapados de oro y plata, guirnaldas del mismo material colocado en sus cabezas; otros llevaban armas y banderas.

\section{Importancia del Inti Raymi}

Es una celebración muy significativa para la comunidad Las Lagunas en donde se recrean las tradiciones y costumbres de la cultura andina, esta festividad se constituye como una manifestación cultural intangible ya que evoca el pasado, permitiendo a través de la recreación, la revitalización y fortalecimiento de la herencia cultural, fundamentalmente de la música, danza, vestimenta y gastronomía, teniendo como objetivo preservar la tradición, esta festividad se realiza con la participación de todos.

\section{Desarrollo de la celebración del Inti Raymi}

Con previa anticipación el cabildo crea comisiones y organizan una serie de actividades nombrando diferentes dignidades para cada acción a realizarse dentro de la fiesta; de esta manera todos los días hay actos planificados y las distintas comunidades se unen a los festejos, estas tradiciones se mantienen intactas por los grupos indígenas que viven en esta zona, conservando y fortaleciendo su legado histórico. Para los saraguros las ceremonias rituales son un conjunto de prácticas, que se han realizado en torno a los diferentes sistemas agrícolas. Su manifestación espiritual se inicia con los rituales relacionadas con el amor a la tierra (proceso de preparación antes de plantar las semillas); luego, continúa con las ceremonias rituales del ciclo agrícola.

Iniciando el proceso de celebración del Inti Raymi, todos los participantes deben considerar la preparación como elemento fundamental para participar en la ceremonia. La preparación incluye elementos como la chicha de fiesta y músicos para la misma, así como invitaciones a todos quienes deseen participar de la celebración.

Vestimenta que se usa en el Inti Raymi. El pueblo Saraguro tiene una vestimenta del diario y una de gala, en la vestimenta del diario utilizan sombrero pequeño, poncho de cualquier color (generalmente negro puro), pero no deja de estar el color negro.

\footnotetext{
${ }^{6}$ Los Kurakas: jefes de los pueblos, comunidades o Ayllus
} 
El día de la fiesta se utiliza la vestimenta de gala, no puede faltar el sombrero de lana, la vestimenta del hombre y de la mujer es negra, el varón lleva una cushma ${ }^{7}$ y un pantalón corto hasta las rodillas; la mujer usa un centro de plisados finos de color negro, blusa bordada en el pecho y puños, sujeto con un túpu de plata. Lleva una gargantilla hecha de mullos de colores que va hasta el filo de los hombros (gola), zarcillos de filigrana y anillos de plata.

Rituales de baño de purificación. Este ritual se lo realiza en el pukllo ${ }^{8}$, además se hace baños de agua caliente con montes aromáticos, y finalmente se hace en una cascada 0 correntada donde puedan participar todos, además se hace un baño del cambio de solsticio a equinoccio a media noche con música y con bailes.

Muruntandana. Es un proceso de recorrido de aviso y pedir el apoyo a la gente, consiste en realizar una visita a todas las familias de la comunidad recolectando granos o cualquier ayuda para los días de la fiesta. Se va con música y bailes para hacer la invitación a esta festividad.

Espiritualidad del Inti Raymi. La espiritualidad del Inti Raymi celebrado como pascua masculina es dedicada al padre sol, a quien se considera como un ser omnipotente engendrador de vida y capaz de quemar todo lo negativo (odios, envidias, rencores, tristezas, sufrimientos, etc.) que existe entre la humanidad. La práctica espiritual del Inti Raymi pretende lograr la máxima purificación de los sentimientos negativos como elemento básico para viabilizar la cosecha de la armonía, la misma que implica también la cosecha de los frutos de la tierra que está directamente relacionada a los logros alcanzados a nivel personal, social, político, económico, cultural y espiritual, en el marco del desarrollo comunitario (Chalán Chalán, 2011).

Traspaso del bastón de mando. es un bastón que en este caso cuando termina la fiesta del Inti Raymi el prioste mayor que es el de Las Lagunas, entrega el bastón a otra comunidad que asume la responsabilidad de celebrar la siguiente fiesta que es el Kulla Raymi, este distintivo será la señal de compromiso para quienes hayan decidido generar un nuevo modelo de estructura social y política.

La Chakana. Es el símbolo de la cruz cuadrada representando el calendario astral, es la cruz andina que, a diferencia de la cruz occidental, tiene igual las 4 puntas. La chakana significa el origen y el ordenador de la vida, aquí se da justo las 4 fiestas Raymi, es decir la ckankana ordena la vida en el mundo andino, porque representa los 4 elementos (tierra, agua, aire y fuego), sin esos elementos no podemos vivir y todo esto da la vida; la chakana para el mundo Saraguro es

\footnotetext{
${ }^{7}$ Cushma: vestimenta autentica del hombre, fabricada con hilo de algodón nativo.
}

8 Pukllo: es donde nace el agua 
una escalera que permite pasar de un mundo a otro y entender al mundo (mineral, vegetal, humano, hombre, mujer) porque todo está conectado el uno con el otro.

La fiesta en la actualidad. Es una de las celebraciones ancestrales más destacadas por las comunidades indígenas en la sierra de nuestro país, la renombrada "fiesta del sol" o Inti Raymi que consiste en una acción de gracias al dios sol y la madre tierra por las fructuosas cosechas de junio. Es así que el 21 de junio, se celebra el día más largo del año, un día cargado de poder y magia en el que los astros se disponen a vivir una fiesta junto a la naturaleza cósmica y el hombre; la celebración del solsticio de verano, tan antigua como la propia humanidad, se convierte en una festividad en donde la algarabía es el detonante de la velada, con saltos y bailes alrededor de fogatas que simbolizan el poder del sol, en un acto de purificación ante influencias demoniacas.

Rol de los dirigentes. Para el festejo del Inti Raymi, se planifica el programa de festividades a través de reuniones conjuntamente con los dirigentes y la directiva de las demás comunidades, en las cuales elaboran el programa general de las fiestas. Gestionan y se organizan para buscar el financiamiento, realizar las elecciones de Akllas ${ }^{9}$, para organizar los grupos de participantes en eventos culturales y deportivos que son planificados para el programa general del Inti Raymi.

En este contexto cabe mencionar que en algunos casos buscar financiamiento depende como sean las relaciones con las autoridades, cuando hay buenas relaciones con autoridades hay un apoyo, pero en años atrás algunos alcaldes siempre han estado en contra del movimiento indígena y no habido un apoyo; en otros casos si es evidente el apoyo, el MINTUR especialmente son quienes apoyan y últimamente la Casa de la Cultura, pero la gran mayoría se hace con auto gestión y con el apoyo comunitario.

Análisis comparativo. Este festejo lo realizaban los antepasados, pero con la colonización y dominación española cambio la forma de celebrarlo logrando la introducción de la religión católica, imponiendo celebraciones religiosas que empezaron a ser parte de la vida en las comunidades, así el Inti Raymi fue sustituido por las grandes celebraciones de San Juan, San Pedro, San Pablo y Corpus Cristi.

El Inti Raymi es una fiesta donde se vive ceremonias, rituales y el pinshimikuna ${ }^{10}$. El Ilincho, Gunudel y Las Lagunas, son las 3 comunidades que aún viven la tradición en Saraguro, lo que permite fortalecer las relaciones entre comunidades, donde se unifican los ritos de purificación de los actores de la fiesta con baños sagrados.

\footnotetext{
${ }^{9}$ Akllas: reinas

10 Pinshimikuna: comida comunitaria
} 
Esta fiesta es en honor a la cosecha de los frutos que da la madre tierra (Pachamama), y también a la relación armónica entre las personas; es decir la cosecha no solo es material, sino también espiritual. Antes, el calendario agrícola estaba determinado conforme con el calendario festivo ya que las fiestas eran organizadas en función de los ciclos de la producción agrícola; en la actualidad, inconscientemente, este calendario sigue vigente y se lo practica, pero las nuevas generaciones no comprenden esta lógica.

El calendario festivo inicia junto con las labores de preparación y culmina con la cosecha y con las primeras siembras del maíz, la programación central son los días 19, 20 y 21, se hace una feria turística y agropecuaria, en donde la comunidad expone su potencial gastronómico, artesanías, medicina natural y promociona los lugares turísticos del sector, en la noche es la coronación de las tres "Akllas", que son como las "reinas" en el mundo español; además de la noche cultural, donde se presentan grupos folklóricos.

Sus pobladores celebran dicha tradición con una variedad de actos como baños de energización, diálogos de saberes sobre el Inti Raymi, exposición de arte y tecnología, concursos de danza, intervenciones artísticas, concurso de comidas típicas, seguido de encuentros deportivos y baños de purificación y al medio día las autoridades centrales hacen el ritual del solsticio de verano. Como tradición sus moradores forman una estrella con cuatro extremos, elaborada con semillas de maíz, fréjol, bananos y demás frutas que producen la madre tierra. En el centro por lo general hay flores y esencias que el Shaman utiliza; también se hace el cambio de mando del Inti Raymi al Kulla Raymi (fiesta de homenaje a la luna) y en la noche se realiza festivales artísticos.

La fiesta dura casi un mes y empieza con un proceso de capacitación espiritual y humano; capacitaciones espirituales con rituales y baños de energización para adultos, dirigentes, niños y jóvenes, los baños se realizan en la madrugada, porque se tiene que cumplir un periodo de agua fría, caliente y tibia, de ahí la persona está preparada para aguantar la celebración. Cabe mencionar que a la celebración del Inti Raymi se ha logrado involucrar a muchos mestizos (extranjeros y nacionales) especialmente de la ciudad de Loja y Cuenca, siendo esta última un sector que ha valorado muchísimo esta celebración. En la actualidad, para la comunidad, esta festividad mantiene su esencia viva, significa el espacio más importante de la espiritualidad, se realiza con la participación de todos desde la planificación y la participación en los actos programados.

Otras prácticas importantes. El Inti Raymi es un espacio de recuperación y de reconstrucción cultural de los saberes y sabidurías andinas, se hacen juegos especialmente para revivir, juegos populares como: concursos de hilado, tejido, cargar leña; en el mundo occidental 
se les dicen juegos, pero en el mundo andino esta son actividades que el niño o la persona iba haciendo para enfrentar los retos de la vida.

Los jóvenes encabezados por el grupo Runa Kawsay hacen campeonatos inter comunidades y las finales son el día 21 en la tarde después del ritual, además se hacen eventos como carreras de motos y de carros de madera, acompañado con noches de danza, música andina que complementan la parte intercultural de la celebración.

\section{Fase 2: Evaluar el potencial del Inti Raymi del Cantón Saraguro de la provincia de} Loja.

Para el cumplimento del segundo objetivo se utilizó la ficha de inventario de "Usos Sociales, Rituales y actos Festivos INPC", que permitió recolectar la información de esta manifestación cultural. Fue indispensable establecer contacto directo con la comunidad y participar como actor participante directo en el desarrollo del Inti Raymi.

La existencia de un ficha en particular se constituye en un registro importante porque permite contar con una línea base para determinar futuras acciones encaminadas a la salvaguardia del patrimonio cultural inmaterial, esta ficha contiene un conjunto de prácticas, manifestaciones y representaciones culturales desarrolladas en un contexto espacial y temporal como celebraciones religiosas y profanas, ritualidades asociadas al ciclo vital de grupos e individuos, que se transmiten de generación en generación con la finalidad de propiciar cohesión social de los grupos (INPC, 2015). Cada ítem de la ficha fue clave para el diagnóstico de la situación e historia de la festividad, así como para determinar el potencial turístico de la festividad.

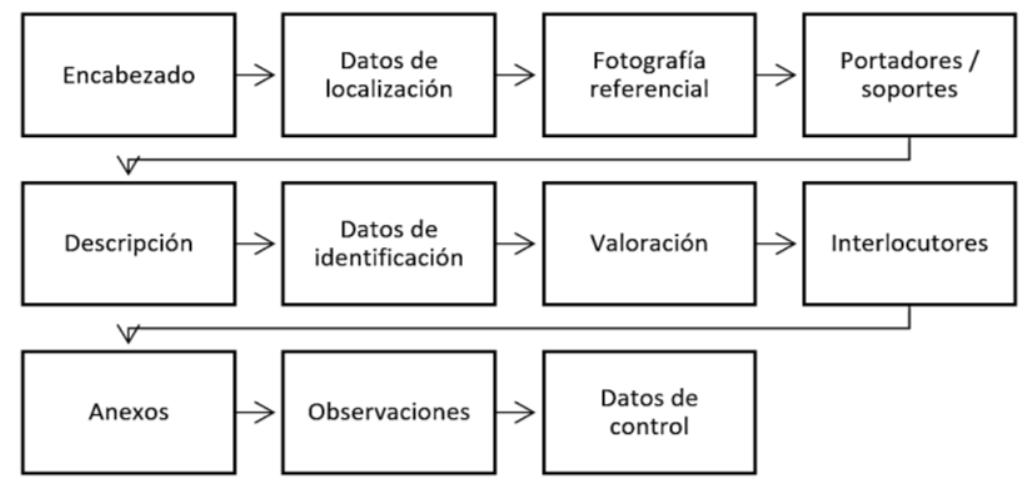

Figura 5. Proceso de ficha de inventario

Fuente: Elaboración propia.

Este apartado también se complementó con métodos y técnicas de investigación como: revisión de bibliografía, diario de campo, entrevistas semiestructuradas, etc. en donde se pudo obtener información histórica y actual referente al desarrollo de la festividad. 
Luego se procedió a socializar con los principales actores involucrados en el taller participativo, donde se obtuvo valiosas observaciones, conclusiones, recomendaciones, FODA, que han servido para encaminar correctamente la realización y cumplimiento de los objetivos de la investigación, además se realizó el análisis de la demanda que permitió determinar la demanda potencial turístico del Inti Raymi.

\section{Análisis de la Demanda.}

Para conocer la demanda potencial del Inti Raymi, se estructuró un cuestionario de 17 interrogantes con un total de 157 encuestas aplicadas, resultado del muestreo en la cual se tomó como referencia a los turistas que asistieron. Teniendo como resultado:

Tabla 7

Datos generales encuestados

\section{Datos generales}

\begin{tabular}{l|c|l|c|l|l|l|l|l|l}
\hline Nacionalidad & $\underline{\%}$ & Residencia & $\underline{\%}$ & Profesión & $\underline{\%}$ & Edad & $\underline{\%}$ & $\begin{array}{c}\text { Nivel } \\
\text { ingresos (\$) }\end{array}$ & $\underline{\%}$ \\
\hline Ecuatoriana & 83 & Loja & 65 & Estudiante & 37 & $15-25$ & 35 & $50-100$ & 33 \\
\hline Extranjero & 17 & Cuenca & 8 & Ingeniero & 28 & $26-30$ & 26 & $301-500$ & 25 \\
\hline Nivel de estudios & \% & Zamora Chinchipe & 6 & Profesor & 17 & $31-35$ & 23 & $501-1000$ & 15 \\
\hline Superior & 59 & Quito & 5 & Comerciante & 6 & $46-50$ & 6 & $101-300$ & 14 \\
\hline Secundaria & 41 & Saraguro & 5 & Diseñador Grafico & 3 & $41-45$ & 4 & $1000-$ más & 13 \\
\hline Género & \% & Riobamba & 4 & Médico & 2 & $36-40$ & 3 & & \\
\hline Femenino & 53 & Ibarra & 3 & Ama de casa & 2 & $51-55$ & 2 & & \\
\hline Masculino & 47 & Guayaquil & 2 & Arquitecto & 2 & $56-60$ & 1 & & \\
\hline & & Bogotá & 1 & Periodista & 2 & & & & \\
\hline
\end{tabular}

Fuente: Elaboración propia.

De acuerdo a los datos obtenidos se determinó que el $83 \%$ de los encuestados son turistas nacionales el porcentaje restante $17 \%$ para turistas extranjeros; la mayoría de turistas son nacionales debido a la cercanía y acceso a la comunidad. De los turistas nacionales el 65\% de las personas encuestadas residen en el cantón Loja; se considera que la afluencia al Inti Raymi por parte de residentes lojanos es porque Saraguro queda a tan solo $64 \mathrm{~km}$ de Loja; pero esto no impide que asisten turistas de otras nacionalidades y lugares de residencia.

El 53\% de asistentes corresponden al género femenino, el $47 \%$ corresponde al género masculino, estos datos se deben a que en el Inti Raymi se realizan varias actividades con expresiones culturales y artísticas de gran interés para las turistas que visitan la comunidad. Además, la edad de los asistentes ronda entre los 15 a 60 años de edad, teniendo como resultado 
mayoritario que el 35\% de las personas encuestadas tienen un rango de edad de 15 - 25 años, 26\% tienen un rango de edad de 26-30 años; el Inti Raymi es una celebración que, por su programación, expresiones culturales y artísticas atrae gente joven que quieren conocer otra cultura.

El 59\% de turistas cuentan con un nivel de estudios superior, $41 \%$ cuenta con un nivel de estudios de secundaria; debido a que el Inti Raymi mantiene un valor cultural muy alto y siendo una celebración con un contenido histórico importante.

\section{Motivación asistir Inti Raymi}

El 35\% de encuestados que asisten al Inti Raymi lo hacen para conocer la cultura indígena, $20 \%$ asiste por fe; el Inti Raymi mantiene su significado, con una gran muestra de identidad, cultura y tradición es así el 39\% de los turistas conoce la fiesta, 19\% los rituales,18\% las costumbres.

El Inti Raymi es una celebración ancestral, con una gran riqueza cultural, es por ello que cada año atrae a un sin número de turistas, el $49 \%$ de los turistas encuestados han asistido varias veces (Figuras 6, 7 y 8). Se comprobó que esta celebración reúne características importantes que permiten a los visitantes regresar nuevamente.

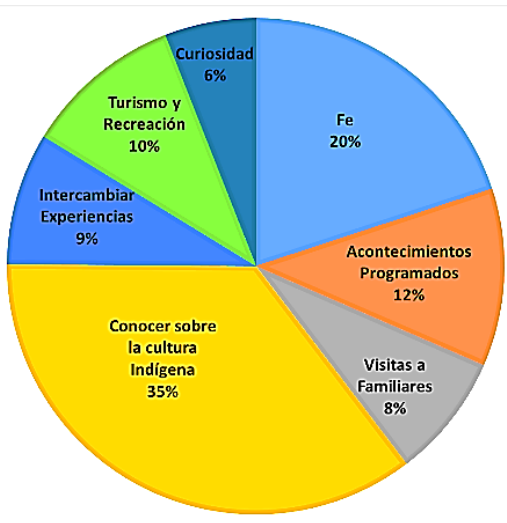

Figura 6. Motivo por el que asiste.

Fuente: Elaboración propia.
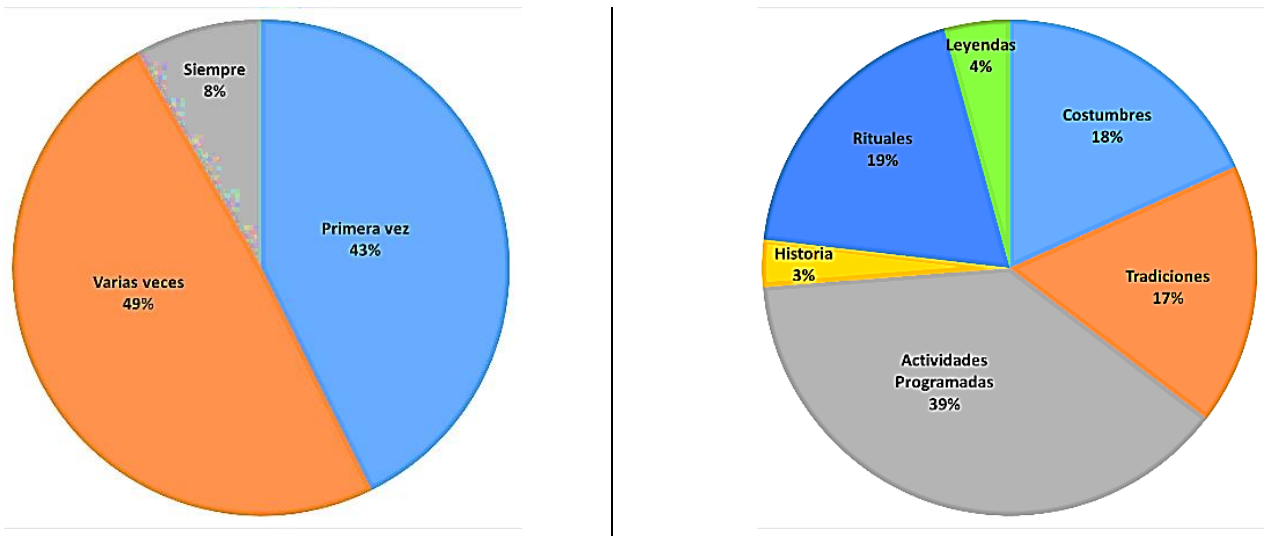

Figura 7. Frecuencia de asistencia.

Figura 8. Conocimiento de la fiesta.

Fuente: Elaboración propia.

Fuente: Elaboración propia. 


\section{Información de acceso al Inti Raymi}

El 39\% de turistas se informaron del Inti Raymi por medio de páginas web, 36\% por medio de familiares y amigos; se determinó que el $53 \%$ asiste con amigos. Es por ello que se considera importante la promoción y difusión por medios orales, prensa escrita y materia publicitaria con el fin de llegar a un mercado objetivo múltiple (Figuras 9 y 10).

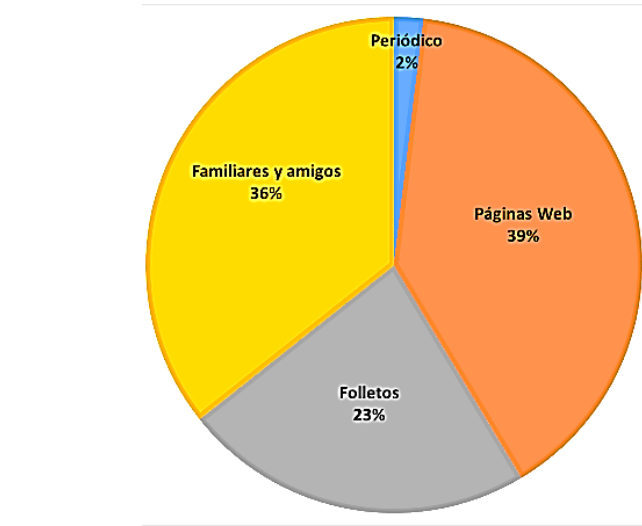

Figura 9. Medio de información

Fuente: Elaboración propia.

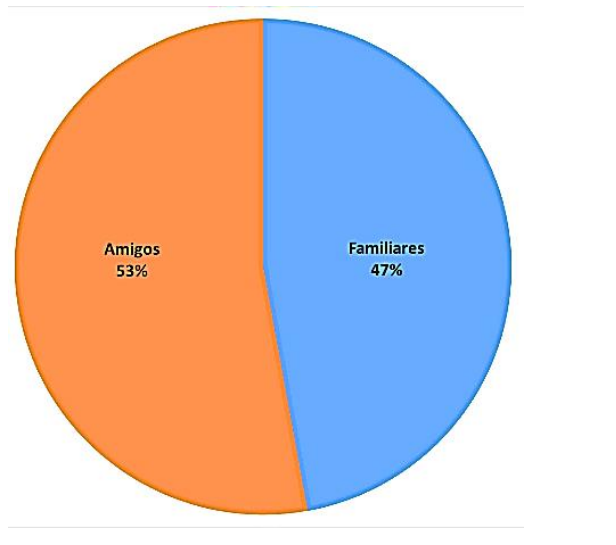

Figura 10. Con quien asiste.

Fuente: Elaboración propia.

\section{Debilidades informativas de la fiesta Inti Raymi}

El 100\% de los encuestados cree que es necesario brindar información del Inti Raymi, ya que el $45 \%$ considera que dentro de las debilidades es precisamente la falta de información una de las más sobresalientes; planteando alternativas de información que abarque los componentes de la fiesta, cultura, costumbres y tradiciones.

El $45 \%$ les gustaría recibir información por medio de video; es necesario plantear una propuesta ya que a través del mismo se puede informar gran contenido de la fiesta, potenciando el turismo en el cantón (Figuras 11, 12 y 13).

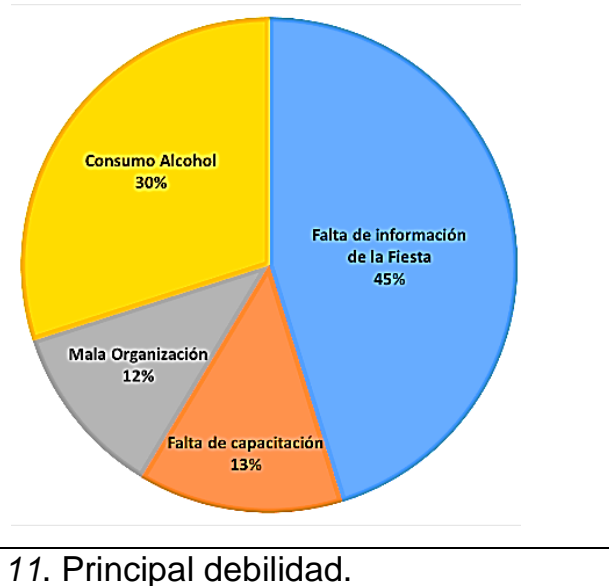

Figura 11. Principal debilidad.

Fuente: Elaboración propia. 


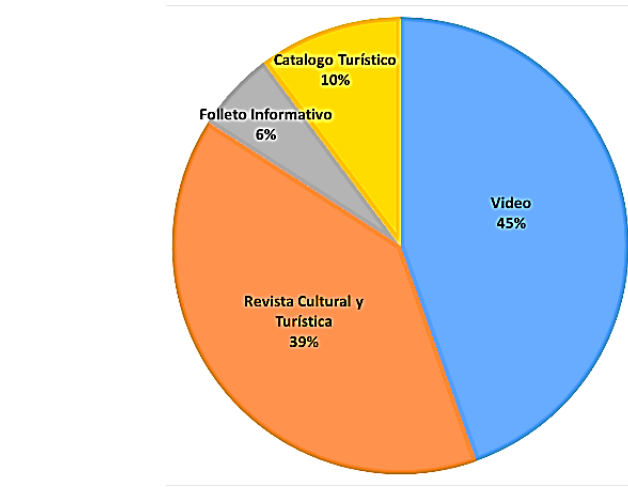

Figura 12. Como le gustaría recibir información de la fiesta.

Fuente: Elaboración propia.

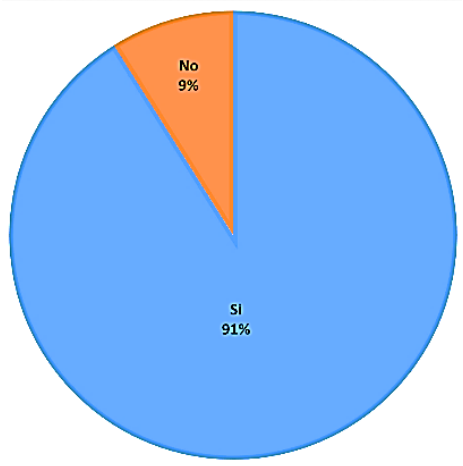

Figura 13. Brindar información de la fiesta.

Fuente: Elaboración propia.

\section{Contenido informativo de promoción}

De acuerdo a los componentes de interés para el turista, el 20\% de turistas les gustaría que el video contenga información general del cantón e historia del Inti Raymi, 19\% que incluir rituales de la festividad, el $18 \%$ considera que debe contener costumbres y tradiciones; y que las características del video deben tener secuencia lógica en su contenido, profundidad en el tema, entrevistas y calidad general (Figuras 14 y 15).

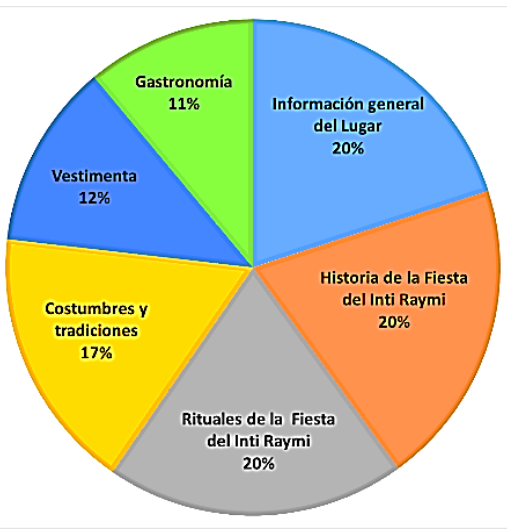

Figura 14. Contenido del video.

Fuente: Elaboración propia.

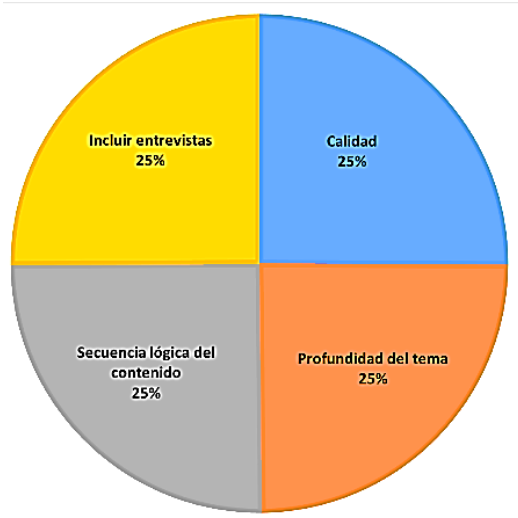

Figura 15. Aspectos del video informativo.

Fuente: Elaboración propia.

\section{Atractivos turísticos en la comunidad Las Lagunas}

El 57\% cuando asiste al Inti Raymi aprovecha para visitar los lugares turísticos; principalmente $49 \%$ de los encuestados conoce el río Chuchuchir, 18\% las artesanías - orfebrería, $9 \%$ conoce la cascada Virgen del Kaka (barrio Oñacápac); el cantón lo convierte en un destino donde se puede realizar varias actividades turísticas teniendo un positivo interés de los turistas; ya que 
Saraguro se caracteriza por la autenticidad de sus comunidades, tradiciones, atractivos y servicios turísticos (Figuras 16 y 17).

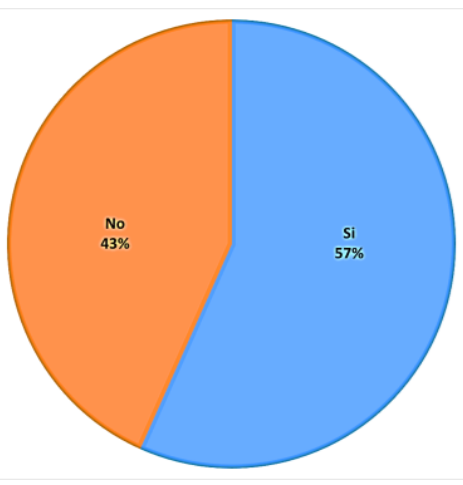

Figura 16. Visita los lugares turísticos de Saraguro. Fuente: Elaboración propia.

\section{Actividad turística vinculada al Inti Raymi}

Estos paquetes turísticos el $26 \%$ sugiere que se realice visitas a los lugares turísticos con guías nativos, $20 \%$ practicar turismo comunitario, $19 \%$ incluir una ruta turística (Figuras 18, 19 y 20).

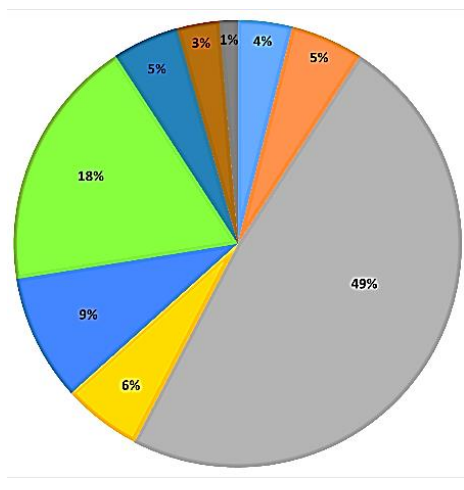

nBosque Protector Huashapamba

«Piedra Ushnu

घRio Chuchuchir

$\square$ Baños del Inka-Comunidad Ñamarin uCascada Virgen del Kaka-Barrio Oñacápac $\square$ Artesanias-Orfebrería 口Telares Folklor Quizhpe uLeón Dormido-Parroquia Urdaneta uTerraza Agricola
Figura 17. Atractivos turísticos que conoce. Fuente: Elaboración propia.

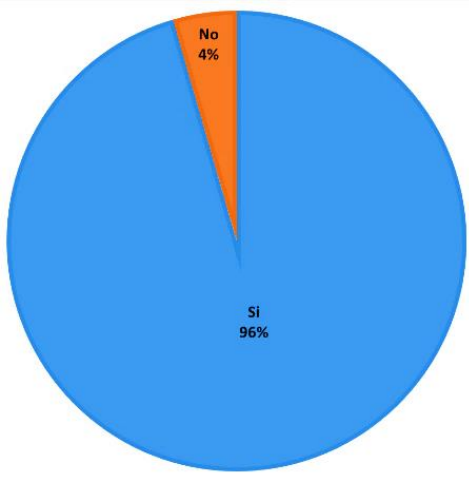

Figura 18. Importancia del Inti Raymi sea vinculada con la actividad turística.

Fuente: Elaboración propia.

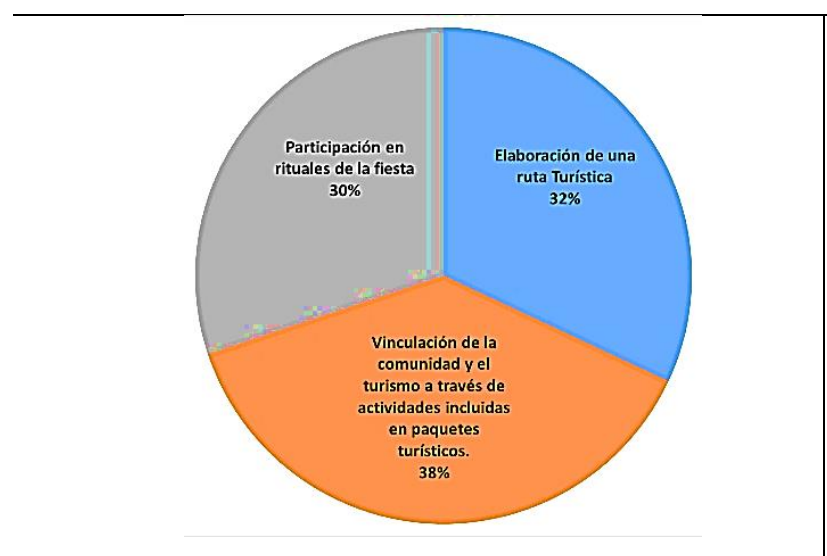

Figura 19. Tipo de programación o actividad turística que se involucre.

Fuente: Elaboración propia.

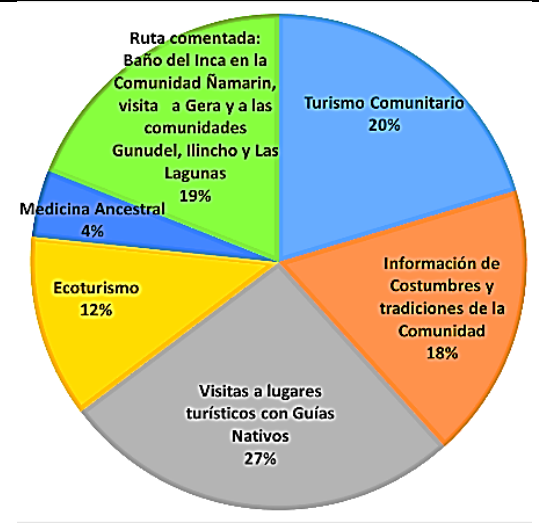

Figura 20. Actividades que sugiere que contenga. Fuente: Elaboración propia. 


\section{Gasto promedio en la fiesta Inti Raymi}

El 27\% en la Inti Raymi gastó en artesanías, $21 \%$ en transporte, 19\% en alimentación y $13 \%$ en actividades turísticas. Y el gasto promedio es de 10 a 39 dólares principalmente; el gasto en artesanías, pone de manifiesto el trabajo hábil artesanal, los indígenas saraguros se destacan por su trabajo que buscan la forma de subsistencia, y el Inti Raymi es una celebración dinamizadora de la economía del sector (Figuras 21 y 22).

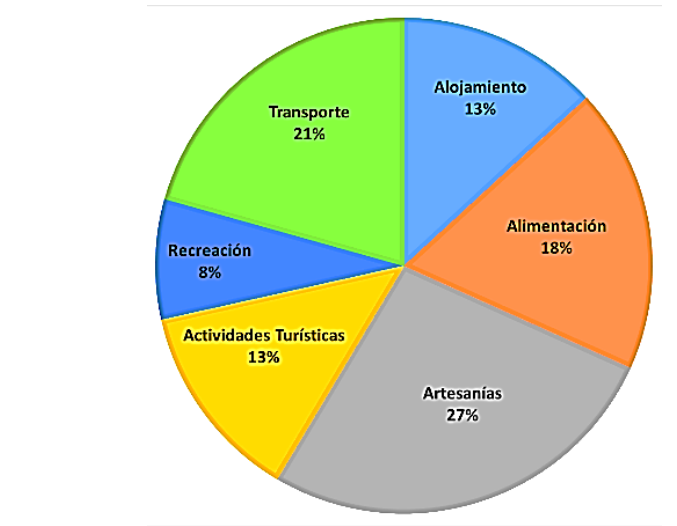

Figura 21. Gastos en su visita a la fiesta.

Fuente: Elaboración propia.

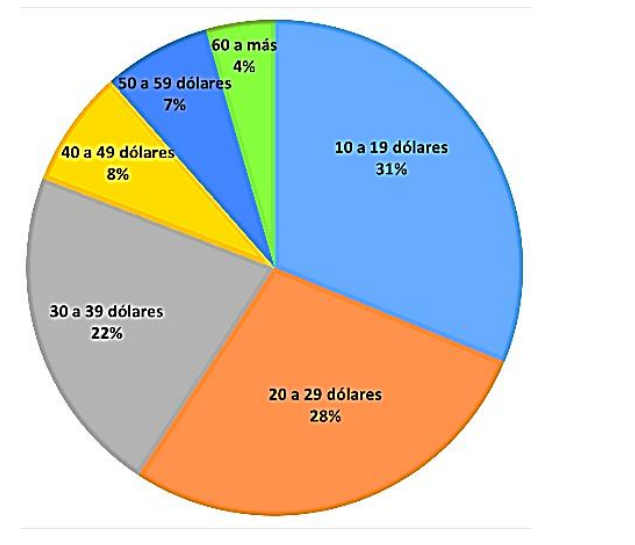

Figura 22. Gasto promedio cuando acude.

Fuente: Elaboración propia.

\section{Método de análisis rápido y planificación participativa (MARPP).}

La opinión de la comunidad receptora es importante, por lo tanto, se organizó un taller participativo en el que se utilizó el método de análisis rápido y planificación participativa. Se trata de un método de investigación participativa y una herramienta de aprendizaje que compensa la omisión de los métodos de investigación tradicionales, el MARPP fue considerado como la mejor estrategia para dar la oportunidad a la comunidad de presentar el conocimiento de su propia situación y condiciones de vida.

Durante el taller se desarrollaron actividades consideradas como herramientas del MARPP; como levantamiento bibliográfico, observación en directo, datos secundarios, entrevistas semiestructuradas, complementos históricos y fotos que permitieron validar la información de la comunidad en estudio, complementando se aplicó el análisis FODA que arrojó resultados que ayudaron a diseñar las estrategias de desarrollo turístico para la comunidad. El taller tuvo la presencia de los actores locales seleccionados en el diagnóstico y fueron convocados; se aplicaron 3 fases a continuación detalladas: 


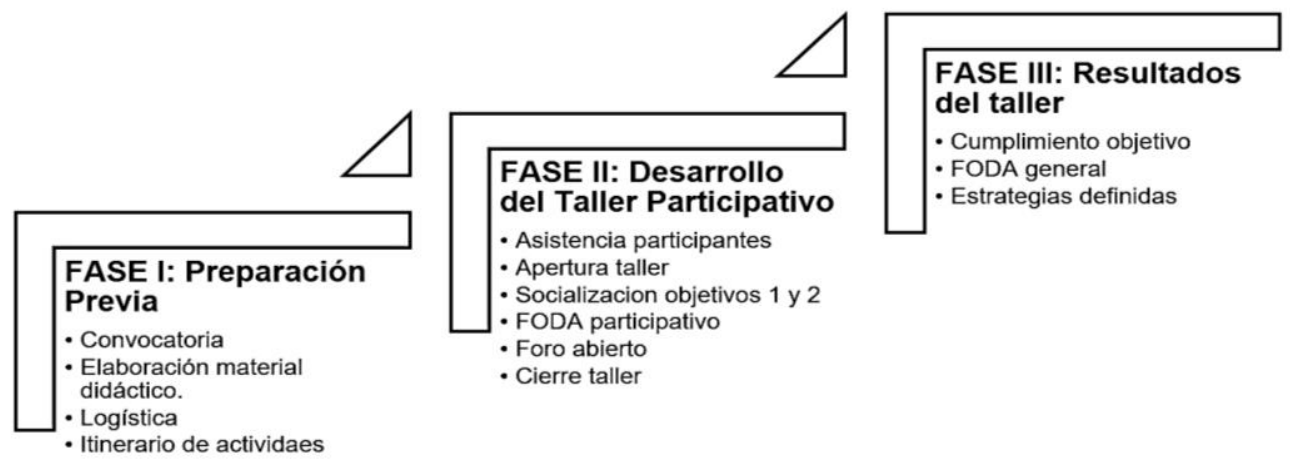

Figura 23. Fases MARPP

Fuente: Elaboración propia.

\section{Análisis FODA del Inti Raymi}

Tabla 8

Habitantes por familias de la comunidad

\begin{tabular}{|c|c|}
\hline Fortalezas & Oportunidades \\
\hline $\begin{array}{l}\text { - Se ha transmitido de generación en } \\
\text { generación realizándola todos los años sin } \\
\text { interrupciones (la tradición no se ha perdido). } \\
\text { - La comunidad posee atractivos turísticos } \\
\text { tanto naturales como culturales. } \\
\text { - La celebración es encabezada por el cabildo } \\
\text { quienes que la difunden a nivel local. } \\
\text { - Inti Raymi permite recrear y vivir todas sus } \\
\text { tradiciones y costumbres heredadas. } \\
\text { - El cabildo cuenta con sub organizaciones } \\
\text { que conjuntamente se encargan de organizar } \\
\text { - Gran acogida y participación de la } \\
\text { comunidad en la festividad. }\end{array}$ & $\begin{array}{l}\text { - Apoyo económico del GAD Municipal de } \\
\text { Saraguro } \\
\text { - Contribuye a la integración y } \\
\text { reconstrucción social, política, cultural y } \\
\text { espiritual de la comunidad. } \\
\text { - Posibilidad de invitar a comunidades } \\
\text { cercanas a participar en la celebración. } \\
\text { - Predisposición de los directivos y } \\
\text { moradores de la comunidad para recibir a los } \\
\text { visitantes. } \\
\text { - Transporte púbico permanente. }\end{array}$ \\
\hline Debil & Amenazas \\
\hline $\begin{array}{l}\text { - Deficiente promoción de la programación a } \\
\text { realizarse en la fiesta. } \\
\text { - Se combina cultura con los elementos } \\
\text { modernos; se mestiza la celebración para generar } \\
\text { aceptación de los jóvenes. }\end{array}$ & $\begin{array}{l}\text { - Falta de conservación de los atractivos } \\
\text { turísticos que posee la comunidad y cantón. } \\
\text { - Turistas o visitantes que buscan ocio y } \\
\text { diversión con alcohol antes que el sentido } \\
\text { cultural-ancestral. }\end{array}$ \\
\hline
\end{tabular}

- Los shows artísticos generan un gasto elevado y crean espacios de consumo de alcohol. 
- No cuentan con un sitio ideal para los rituales, las vías de acceso están en mal estado

- Pérdida del sentido cultural-ancestral (prima el consumo de alcohol)

- Alta migración del campo a ciudades aledañas o países extranjeros.

- Escasa infraestructura y servicios turísticos.

- Falta de servicios sanitarios en la comunidad.
- Se realiza actividades no tradicionales o ancestrales sino modernas y no propias de la comunidad o cantón.

Fuente: Elaboración propia.

\section{Validación de la Información}

Dentro del taller organizado se verificó la información obtenida del desarrollo, historia, componentes, rituales, costumbres y tradiciones del Inti Raymi, se sugirió incrementar información de los atractivos turísticos de la comunidad. Finalmente, de acuerdo a la información de las 2 fases de la investigación y análisis de las encuestas y el análisis del taller participativo se constató la factibilidad del desarrollo de una propuesta que fomente la participación de los visitantes en el Inti Raymi, ya que guarda historia y manifestaciones culturales que merecen ser fortalecidos, difundidos y celebrados.

Tabla 9

Componentes de estrategias definidas

\begin{tabular}{c|c}
\hline Componente & Estrategias \\
\hline Comunicación & $\begin{array}{c}\text { Posicionamiento del Inti Raymi- comunidad Las Lagunas como fiesta } \\
\text { ancestral, cultural y turística (Video informativo y revista turística-cultural). }\end{array}$ \\
\hline Capacitación & Fortalecimiento de las capacidades locales para el desarrollo turístico. \\
\hline Infraestructura & Mejoramiento de los sitios de interés turístico. \\
\hline Facilidades & Planificación y ejecución de paquetes turísticos: “Saraguro tierra \\
turísticas & marticipación \\
ciudadana & Fortalecimiento de la participación ciudadana y cooperación \\
\hline
\end{tabular}

Fuente: Elaboración propia - Taller FODA.

\section{ANÁLISIS DE RESULTADOS}

La investigación contribuyó al desarrollo turístico y cultural, a través de la recolección de información de campo, análisis y sistematización de resultados, logrando aportar con estrategias de desarrollo y mejoramiento turístico para la comunidad. La falta de una propuesta de estudio, 
documentación, difusión y promoción del Inti Raymi, como patrimonio cultural inmaterial y recurso turístico del cantón Saraguro, no ha permitido que el turismo cultural se desarrolle a través de un modelo sustentable y organizado, provocando una serie de impactos negativos en Las Lagunas.

El enfoque del desarrollo sostenible, sustentable y desarrollo del turismo de patrimonios culturales inmateriales tiene como objetivo mejorar el medio ambiente mediante la satisfacción de las necesidades de las comunidades sin comprometer la capacidad de las generaciones futuras para satisfacer sus propias necesidades (WCED, 1987, p. 8).

Establecer turismo cultural sustentable en Las Lagunas contribuye al desarrollo de la comunidad si los agentes y empresas del turismo son eficientes, equitativos y orientados al medio ambiente. MacDonald y Lee (2003) examinaron el turismo rural cultural teniendo en cuenta el papel de la cultura en las asociaciones de base comunitaria; lo que se pudo evidenciar en la comunidad y festividad analizada que sugieren que la cultura en el desarrollo del turismo rural es un recurso valioso y las asociaciones de base comunitaria pueden ser eficaces, representando una oportunidad a través del Inti Raymi y la participación activa de la comunidad, contribuir al desarrollo territorial.

El Inti Raymi es la celebración más importante y representativa del año en la comunidad Las Lagunas, tiene un gran valor histórico, está perdiendo el interés por parte de la juventud; de los datos extraídos de la realidad social del sector y de acuerdo a la escasa documentación se decidió analizar desde el enfoque de análisis rápido y planificación participativa; que ayudó a establecer los antecedentes, desarrollo y fortalecimiento de la celebración con la participación activa de los actores comunitarios.

El Inti Raymi en su proceso histórico ha sufrido importantes cambios en cada época, sin embargo, aún en la actualidad esta fiesta reivindica la participación de sus personajes, indumentaria, comidas, formas de festejo; manteniendo el vigor y energía de sus celebraciones con toda devoción. Las investigaciones realizadas de estas temáticas se han limitado a abordar el fenómeno de modo descriptivo o hacia la identificación de los principales significados generados por la tradición, sin permitir captar desde lo comunitario los procesos de participación y cooperación alrededor del proyecto colectivo como principio del desarrollo cultural. En tal sentido, es necesario que la expresión de lo comunitario se distinga a través de procesos de participación, cooperación y asunción consciente y crítica de la práctica social, la definición de comunidad se convierte en el eje articulador para comprender los vínculos en los cuales se basa lo comunitario como manifestación del sistema de relaciones sociales (Escudero, 2017).

Para el estudio se estructuró el marco teórico analizó el patrimonio cultural como parte del desarrollo turístico, se entrevistó al presidente de la "Red de turismo comunitario Saraguro Rikuy" 
y al representante de la comunidad educativa del "Inti Raymi” obteniendo información eficaz y precisa, misma que fue introducida a la ficha de inventario de usos sociales, rituales y actos festivos (INPC) que ayudó a explorar y detectar cómo se encuentra la estructura de la fiesta y poder evaluar correctamente la situación actual del evento. Es importante mencionar que esta festividad es la más importante del año, a pesar de ello el GAD no promociona dicho evento, la difusión de esta festividad es clave porque permitirá integrar la fiesta a través de turismo, gastronomía y artesanías del pueblo, obteniendo resultados satisfactorios para la comunidad, permitiendo generar turismo en la localidad y que ayudará al desarrollo socioeconómico, donde se podrá dar a conocer los diferentes tradiciones y costumbres.

Es así como esta celebración recoge la riqueza de la cultura ancestral mostrando al público las tradiciones y costumbres de este pueblo, que conjuga el esplendor del pasado y presente del pueblo Saraguro, siendo verdadero ejemplo de nuestras raíces; los resultados de esta investigación son satisfactorios, porque ha contribuido a fortalecer el turismo de esta localidad mediante las experiencias teórico-práctico planificadas.

\section{CONCLUSIONES}

Durante el proceso de desarrollo de la investigación, se encontró hitos importantes que deben ser tomados en cuenta, ya que representan una realidad perceptible del valor cultural y ancestral del Inti Raymi; que son fundamentales para contribuir al desarrollo local de la comunidad a través del turismo.

El Inti Raymi, lejos de permitir la celebración de la nación pluricultural indígena, se puede considerar que permite la continuidad de los procesos de folclorización, mientras se invisibilizan los problemas reales que afrontan los pueblos indígenas; sin embargo, la historia muestra la fortaleza y lucha de los pueblos indígenas por mantener su identidad en el tiempo y legitimar sus derechos; la celebración del Inti Raymi es una forma de mantener viva su cultura, ya que de una u otra manera en la colonia los españoles impusieron sus celebraciones dejando de lado a las celebraciones de los pueblos indígenas.

Inti Raymi es una experiencia de tipo vivencial, si no se la vive en carne propia, muy probablemente no se la entenderá; solo participando en esta celebración se puede tener el conocimiento que esta transmite - la fiesta del dios sol, como eje que direcciona la vida y a la sociedad, para el mundo andino y relacionado con los ciclos agrícolas. En junio, todos están esperando el encuentro y celebración del Inti Raymi, agradeciendo al sol y a la madre tierra por sus generosas donaciones durante el año o ciclo, no olvidemos que la mayoría de las personas que siguen viviendo en la comunidad se dedican a la agricultura, al igual que a la ganadería, y 
los ancianos, jóvenes, mujeres y niños celebran al sol y la madre tierra de manera alegre, que son parte de la vida de las comunidades indígenas.

En la década de 1970, el Inti Raymi estaba al borde de la extinción, los ancianos de la comunidad y algunos de sus herederos recordaban con pesar la gloria de esta tradición, que paulatinamente fue desapareciendo. Afortunadamente, la persistencia de su mensaje, la vitalidad de los ritmos y bailes de sus antepasados, y su espiritualidad, han impulsado a la nueva generación a restaurar este patrimonio cultural, hoy consolidado en todos los aspectos.

Esta celebración se sigue celebrando con fervor, el mismo que se realiza cada año con todos sus matices, costumbres y actores que reviven esta celebración, para la cual los participantes se preparan adecuadamente para disfrutarla en toda su magnitud; ya que es una forma de demostrar y rescatar su identidad sobre la población mestiza, que poco a poco se va fusionando con los sectores indígenas por cuestiones de trabajo y convivencia.

Con el paso del tiempo vendrán cambios, podemos estar seguros que los cambios políticos el sector indígena ha recuperado su lugar, lo que significa recuperar sus derechos de gestión sobre sus propias comunidades y jugar un papel importante en ellas y en el escenario político del país. En Las Lagunas existe la necesidad de rescatar y fortalecer la cultura ancestral para que realmente el habitante y hasta el turista pueda sentirse dentro de la misma y así disfrutarla, enaltecerla y permitir que siga creciendo. Además, se identificó que la comunidad Las Lagunas y el cantón Saraguro posee recursos naturales y culturales que pueden ser aprovechados, mediante el desarrollo de la actividad turística siendo uno de ellos el Inti Raymi.

Es importante señalar que con el tiempo esta celebración atrae a más personas, no solo de la comunidad andina, sino de todo el mundo; en Ecuador, la mayoría de las provincias de la sierra lo celebran, y cada provincia cambia ciertas características acorde a su zona de forma diferente, pero con el mismo propósito. En Las Lagunas cada familia se prepara con anticipación, se busca inspirar a los más jóvenes a aprender a tocar instrumentos musicales o participar de los rituales; de esta manera, los nuevos actores se integran a la celebración de la fiesta, pero también buscan la identidad a su manera, adaptados a la modernidad, incluso muchas veces, se lleva a cabo bajo la presión y obligación de los padres. Cada año esta lucha se da, cuando las nuevas generaciones crecen, y lo hacen con sus propias preocupaciones y necesidades.

Otro punto destacado es la presencia, liderazgo organizacional de la dirigencia indígena comunitaria de Las Lagunas, en los aspectos logísticos y de seguridad; pero las familias ya conocen su rol de participación en las diferentes actividades o grupos responsables sobre todo en los temas de alimentación con los propios productos cosechados es sus territorios y dados por la madre naturaleza. 
Finalmente es importante que todas las manifestaciones de identidad se den en el mutuo respeto para que puedan perpetuarse en el tiempo, y motivar e inspirar a los jóvenes para que se vayan insertando en la misma, al igual que las mujeres que ya tienen una participación directa y muy decidida en la misma comunidad.

\section{REFERENCIAS BIBLIOGRÁFICAS}

Asamblea Nacional. (11 de Agosto de 2013). Código Orgánico de Organización Territorial, COOTAD. Ministerio de Coordinación de la Política y Gobiernos Autónomos Descentralizados, Quito. Obtenido de Código Orgánico de Organización Territorial, COOTAD. Recuperado de http://www.defensa.gob.ec

Cartuche, D. V., \& Bastidas, M. (2017). Propuesta de un escenario turístico medicinal en el territorio de la cultura saraguro en la provincia de Loja. Revista Turydes: Turismo y Desarrollo, n. 23. Obtenido de http://www.eumed.net/rev/turydes/23/cultura-saraguro.html

Centro Regional de Investigaciones Multidisciplinarias. (2013). Experiencias de salvaguardia del patrimonio cultural inmaterial . Cuernavaca: Centro Regional de Investigaciones Multidisciplinarias, Universidad Nacional Autónoma de México.

Chalán, Á. P. (2011). PACHAKUTIK: La vuelta de los tiempos. Saraguro, Ecuador: Fundación Jatun Kawsay.

Chávez, R. M., \& Andrade, E. (2002). La búsqueda del yo en el entorno natural y cultural del otro. Congreso Virtual Internacional de Cultura y Turismo. Naya-Ciudad Virtual Antropológica. Recuperado de www.naya.org

Comunidad Lagunas. (2010). Estado plurinacional del Ecuador, Nuevo Estatuto de Chukidel Ayllullakta Comunidad Las Lagunas. En N. E. Lagunas, Plan de Desarrollo Comunitario. Saraguro.

CONAIE. (1988). Las nacionalidades indígenas en el Ecuador. Quito. Recuperado de https://www.fes-ecuador.org/fileadmin/user_upload/pdf/0121\%20NACIND1986_0121.pdf

Engels, F. (1996). El origen de la familia, de la propiedad privada y del estado: La Gens y el Estado en Roma (Vol. 13era edición ed.). Madrid, España: Editorial Fundamentos.

Escudero, C. L. ( julio - septiembre de 2017). Las fiestas populares en el Ecuador: un factor de interacción comunitaria. Universidad y Sociedad vol.9 no.3 Cienfuegos. Recuperado de http://rus.ucf.edu.cu/index.php/rus

Explorable. (24 de Julio de 2018). www.explorable.com. Recuperado de https://explorable.com/es/diseno-de-investigacion-descriptiva 
Fundación Dra. Silvia Macotela. (24 de Julio de 2018). http://www.psicol.unam.mx/. Recuperado de http://www.psicol.unam.mx/Investigacion2/pdf/METO2F.pdf

GAD Municipal Intercultural de Saraguro. (2016). PLAN DE DESARROLLO Y ORDENAMIENTO TERRITORIAL DEL CANTÓN SARAGURO. Saraguro.

INPC. (2011). Instructivo para fichas de registro e inventario Patrimonio Cultural Inmaterial. Recuperado de http://issuu.com/riesgosinpc/docs/www.inpc.gob.ec

INPC. (2015). Patrimonio Cultural Inmaterial.

MacDonald, R., \& Lee, J. (April de 2003). Cultural rural tourism: Evidence from Canada. Annals of Tourism Research, 30 (2), 307- 322.

Prats, L. (1997). Antropología y patrimonio. Madrid: Ariel.

Ricaurte, C. (2009). Manual para Diagnóstico Turístico Local. Guayaquil.

Santana, A. (1997). Antropología y turismo ¿nuevas hordas, viejas culturas? Barcelona-España: Ariel.

Silva Charvet, E. (2005). IDENTIDAD NACIONAL Y PODER (Vol. 2da. Edición). Quito: Abya Yala.

SINNAPS. (24 de Julio de 2018). Empresa - Gestor de Proyectos. Obtenido de https://www.sinnaps.com/blog-gestion-proyectos/metodologia-cualitativa

Skoczek, M. (1998). El turismo como factor del desarrollo local en América Latina. Separata de: Actas L. de V., tomo 21.

Troncoso, C., \& Almirón, A. (2005). Turismo y patrimonio: Hacia una relectura de sus relaciones. Aportes y Transferencias, 1(009), 56-74.

UNESCO. (2003). CONVENCION PARA LA SALVAGUARDIA DEL PATRIMONIO INMATERIAL, Art.2, Num. 1. Obtenido de https://ich.unesco.org/es/convenci\%C3\%B3n

UNESCO. (2003). PATRIMONIO CULTURAL INMATERIAL. Recuperado de https://ich.unesco.org/es/que-es-el-patrimonio-inmaterial-00003

WCED. (1987). Our Common Future. Oxford: Oxford Publishers. 